Methods A research was carried out on the historical line on the stigma also on the guidelines of public assistance to mental health in the units of care for the patient with mental disorders and the database on disease and concession of social security benefit due to mental disorder in Brazil

Results Stigma is prejudice itself, causing irreparable losses to patients and their many aspects. In addition, it is intended to emphasise the need to combat prejudice to the mentally ill, showing that our main weapon is correct information. The public mental health assistance policy is ineffective. In 2014 there were 12.235 concession of social security benefits due to mental disorder in Brazil, with 28\% for Depressive episods. Discussion Much of this process occurs because of the inherent characteristics of the disease process, such as psychotic episodes, dissociative episodes, among others, that end up labelling and making life difficult for those with mental illness with no mental health assistance causing work absenteeism and high costs to the Security and Social National Institute.

\section{THE THRIVE PROGRAM FOR ACHIEVING HOLISTIC WELLBEING \& WORK-LIFE BALANCE. SHARING EXPERIENCE FROM HINDUSTAN UNILEVER LIMITED, INDIA}

${ }^{1}$ Kishore P Madhwani, ${ }^{2} \mathrm{HV}$ Ravimohan, ${ }^{3}$ Sudip Gupta, ${ }^{1}$ Mira Santiago, 'Sunita Vazir. ${ }^{1}$ Hindustan Unilever Limited, Mumbai, India; ${ }^{2}$ Hindustan Unilever Limited, Bangalore, India; ${ }^{3}$ Hindustan Unilever Limited, Kolkata, India

\subsection{6/oemed-2018-ICOHabstracts. 1595}

Introduction As employees are its greatest asset, Hindustan Unilever Limited (HUL) launched THRIVE PROGRAM in 2016 for achieving their holistic well-being to thrive in this VUCA world with aim of strengthening Wellbeing. Mental Health is given same priority as Physical health vide HUL's Mental Wellbeing Standards (Policy).

Methodology Thrive Program is structured for HUL workforce comprising of Managers, Executives and factory workers $(n=18558)$. Managers and Executives completed on-line training modules and subsequently attended THRIVE WORKSHOPS, conducted by Trainers (from $\mathrm{HR}$ and $\mathrm{MOH}$ ) who were trained by Expert Faculty on a globally uniform curriculum. THRIVE is designed on 4 Pillar Wellbeing Framework (4PWF): mental, physical, emotional and purposeful providing practical solutions to sustain each wellbeing area to cope with pressures, while feeling focused, energised and maintaining work-life balance. All employees' including factory workers had access to EAP counselling line $24 \times 7$ manned in nine languages by qualified counsellors. Subsequently, WELLBENG WEEK was initiated showcasing different ways to leverage (4PWF), following which Wellbeing Wednesdays were launched with 40 activations where 7000 employees participated in key events on Fitness, Ergonomics, healthy nutrition choices and recreation.

Results In 2016, 6257 employees completed modules 0.11160 attended Thrive sessions [5264 factory workers and 5896 white collar with following feedback ( $n=866$ participants); 98\% could understand Unilever Wellbeing Framework, of which 37\% rated it above average; 93\% rated course content, material delivery, instructor skills and knowledge above average, $72 \%$ felt that instructor presented the material clearly indicating effectiveness of the program model. $65 \%$ are confident of applying what they had learnt and 58\% would recommend this course to colleagues.
Discussion Every organisation must have a MENTAL HEALTH POLICY for achieving holistic wellbeing and worklife balance. Initiatives like THRIVE PROGRAM and WELLBEING EVENTS are successful with good participation because of uniform curriculum for worker groups, followed globally in every country.

\section{PSYCHOSOCIAL CONSTRAINTS AMONG MEDICAL AND PARAMEDICAL CAREGIVERS ON INTENSIVE CARE UNITS}

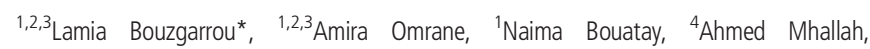
${ }^{2}$ Selma Kammoun, ${ }^{1,3}$ Awatef Kreim, ${ }^{1,3}$ Taoufik Khalfallah. ${ }^{1}$ Department of Occupational Medicine and Ergonomics, Faculty of Medicine of Monastir; ${ }^{2}$ Research Unit: 12SP39, University of Monastir; ${ }^{3}$ Occupational Medicine Department, Taher Sfar University Hospital, Mahdia; ${ }^{4}$ Psychiatrie Department, Fattouma Bourguiba, University Hospital, Monastir, Tunisia

\subsection{6/oemed-2018-ICOHabstracts.1596}

Introduction Health care professionals, particularly intensive care teams, are exposed to psychosocial constraints. This study aims to identify socio-demographic and occupational determinants of work-related stress and workplace harassment.

Methods A three months cross-sectional exhaustive study conducted among medical and paramedical staffs of intensive care units in two university hospitals in the centre of Tunisia. Four validated scales were used (Karaseck's Job Content questionnaire, Negative Acts Questionnaire, Rosenberg, Beck and Hamilton Anxiety scale).

Results Moral harassment was objective among $38.33 \%$ of caregivers and $15 \%$ of them were in situation of job strain. Moreover, $61.7 \%$ of them were depressed, anxiety disorders were detected in $49.9 \%$ of cases, and low or very low selfesteem was noted among $40 \%$ of respondents. According to multivariate analysis, job strain was correlated with young age $(p=0.005)$ and shorter work seniority $(p=0.001)$. Workplace harassment was more prevalent among females $(p=0.009)$, resident physicians $(p=0.021)$, those affected to atypical schedules $(p=0.008)$, anxious subjects $(p=0.004)$ and those with low to moderate self-esteem $(\mathrm{p}=0.002)$.

Discussion Psychological and social constraints among intensive care staff should be preventive in order not to affect health and wellbeing of caregiver or security or quality of care.

\section{CLINICAL OCCUPATIONAL MEDICINE: A METHODOLOGICAL FRAME FOR DAILY PRACTICE IN OCCUPATIONAL HEALTH}

Quentin Durand-Moreau*. Occupational and Environmental Diseases Centre, University Hospital of Brest, Brest, France

\subsection{6/oemed-2018-ICOHabstracts. 1597}

Objectives Work-related mental disorders are often spontaneously described by workers as the result of bullying. In France, this phenomenon has emerged in 1998 parallel to the concept of perverse-narcissistic personality. Considering these situations only as the result of an intersubjective experience puts the working conditions themselves far away. But the working conditions may be responsible for such disorders in a three-dimensional view of activity (the self, the others and the work object) as described by Clot and Kostulski (2011). Our aim is to describe a method, using a relevant case-report, to 
better understand the links between work and mental health issues.

Methods Clinical occupational medicine is a way to practice occupational medicine. This method allows the patient and the occupational physician to work by referring to concrete events or remembrances in order to better understand the links between work and health. The clinician seeks to switch from the talking points to the real thoughts of the patient. We perform these consultations to help occupational physicians to evaluate the workers' fitness for their job, or to help workers suffering from work-related mental disorders to obtain compensation.

Results Mrs Q, aged 58, worked as a medical secretary for a general practitioner. She accused him of bullying and was on sick leave. She was previously a housewife during 10 years and before she had a job experience in catering. Her husband has helped her to get this job. She worked during 11 years with an old GP. She had no training to be a medical secretary, but she did not have any trouble to work. It was the old way, with paper files and schedule. This GP has retired and was replaced by a young one - the new way, with computerised files. The secretary started being in trouble: she delivered medical files to right-owners concerning old patients living in retirement houses regardless to the legal considerations and provided a risk of prosecution for the GP. She was also in trouble with the use of computers. In fact, she felt bullied whereas her employer was accusing her of mistaking. On the other hand, her employer has never asked her if she was in trouble and never proposed any help.

Conclusion The spontaneous speeches from patients often give intersubjective explanations to their work-related mental disorders. Thus the easier way to answer the problem is to eliminate the bully. However, the work object or conditions may drive someone into a bullying behaviour. Having a threedimensional approach allows proposing more efficient solutions, more tailored to individual situations (e.g. a specific training). The clinical practice allows guiding patients who present psychiatric disorders. This case-report also illustrates the huge gap between spontaneous speeches ('I am bullied') and the clinical work performed by a physician or a psychologist. Regarding this fact, we should be very cautious when using self-administered questionnaires.

\section{PROBLEMATIC DRINKING BEHAVIOUR AMONG BELGIAN WORKERS: PREVALENCE, HEALTH AND JOB RELATED CONSEQUENCES}

\footnotetext{
1,2 Marie-Claire Lambrechts*', ${ }^{3}$ Lieve Vandersmissen, ${ }^{1,3}$ Lode Godderis. ' $\mathrm{KU}$ Leuven, University of Leuven, Centre Environment and Health, Belgium; ${ }^{2}$ VAD Flemish centre of expertise on alcohol and other drugs, Brussels, Belgium; ${ }^{3} / d e w e$, External Service for Prevention and Protection at Work, Heverlee, Belgium
}

\subsection{6/oemed-2018-ICOHabstracts. 1598}

Introduction Only few data on the (problematic) use of alcohol in workers and possible job related effects are available.

Methods In 2016 an anonymized questionnaire was filled out by Belgian employees while waiting for a periodical occupational health screening. The Alcohol Use Disorders Identification Test- Consumption (AUDIT-C) was used to measure prevalence of alcohol consumption. Also, the effects on absenteeism, lost productivity, workplace accidents, conflicts with co-workers and sanctions by employers were investigated. Result 5367 workers completed the questionnaires. $37.1 \%$ of last year drinkers $(n=4197)$ drank more than once a week; $36.4 \%$ with an average daily consumption of 3 to 4 units, $11.4 \%$ with $\geq 5$ to 6 units. Respectively $22.7 \%$ and $7.8 \%$ exhibited binge drinking at least once a month/week. Based on AUDIT-C 39.1\% of last year drinkers had an indication of problematic drinking. This was significantly higher among higher educated and male employees $<35$ years. In the construction industry, $51.6 \%$ of last year drinkers had an indication of problem drinking. $12.2 \%$ of last year drinkers experienced consequences on the job. $27.8 \%$ observed negative effects among their colleagues, especially being late at work (18.3\%), irregular job performances (18\%), absenteeism $(15.7 \%)$ and conflicts with colleagues $(10.6 \%)$. There is a significant relation between the AUDIT-score and job related effects $(\mathrm{p}<0,001)$. Being single, age $(<35$ year $)$ and specific work environments were risk factors: $23.5 \%$ of workers within the construction industry, $17.8 \%$ within the catering industry and $17.1 \%$ within the transport sector experienced consequences at the workplace in the past year. We did not found correlations between the AUDIT-C score and job stress, satisfaction, recognition and variation.

Discussion Overall results show that problem drinking among workers is a typically male issue. Given the negative impact of work, a tailored and multicomponent alcohol policy in different sectors need to be implemented.

\section{IMPROVEMENTS IN THE PROFILE OF MOOD STATUS AFTER PARTICIPATION IN THE SHORT-VERSION CLIMATOTHERAPY PROGRAMME AMONG JAPANESE WORKERS}

H Kanayama*, Y Kusaka. University of Fukui, Eiheiji-cho, Japan

10.1136/oemed-2018-ICOHabstracts.1599

Introduction Today, Japanese workers cannot have enough leisure time. According to the latest Survey on Industrial Safety and Health, number of the employees of sick leave or turnover with mental disorders was 343 thousand per year. Percentages of the people with regular physical exercise are markedly lower in working generation compared to retired generation. In Germany, several companies contract with the institute of universities or states and offer once 'climatotherapy week' per year for disease prevention and health promotion of workers. We had originated the short-version climatotherapy programme to fit anyone who has no enough time.

Methods Our short-version climatotherapy programme was conducted in 2015 at Asuwayama Mountain. Physiological and environmental data collection was conducted. Participants answered the questionnaire on physical condition and exercise habits, the questionnaire on the work styles and job stress, subjective temperature sensation during climatotherapy, and Profile of Mood Status (POMS) brief form Japanese version before and after climatotherapy. Data were analysed using SPSS.

Results Sixteen inhabitants (9 males, 7 females; mean age 51.8 years) were participated, and their work styles were ordinary 